\title{
Sputum cytology in the diagnosis of pulmonary non-Hodgkin's lymphoma
}

\author{
A MANOHARAN, J FORD, J HILL, D PAINTER, D MILLER \\ From the Division of Clinical Haematology, Department of Medicine, and Division of Anatomical and \\ Cytopathology, Department of Pathology, St George Hospital, University of New South Wales, Sydney, \\ Australia
}

Pulmonary disease in non-Hodgkin's lymphoma is known to occur in $10-25 \%$ of patients, ${ }^{2}$ but the exact diagnosis during life remains difficult and usually depends on exclusion of other possibilities - for example, infection and haemorrhage-or the use of techniques such as fibreoptic bronchoscopy, bronchial brushing, and needle biopsy. ${ }^{3}$ Cytological examination of the sputum, which is a much simpler and a non-invasive investigation of proved efficacy in patients with bronchogenic carcinoma, is seldom used in patients with suspected intrathoracic non-Hodgkin's lymphoma. In this report we describe two patients with nonHodgkin's lymphoma with pulmonary involvement in whom the sputum was positive for lymphoma cells.

\section{Case reports}

CASE 1

A 64 year old woman first presented to the clinical haematology unit in January 1982 after the diagnosis of non-Hodgkin's lymphoma. She was known to have had Sjögren's syndrome since 1970 , with several exacerbations of arthritis during the next 10 years. A routine chest radiograph performed in May 1981 showed multiple round opacities, but percutaneous fine needle aspiration of the most posterior lesion failed to establish its nature. She remained well until December 1981, when she presented with episodic lower abdominal pain and was found to have a pelvic mass. At laparotomy a benign ovarian cyst was found. The surgeon also noted the presence of several pale and rubbery lesions in the transverse colon and ileocaecal junction as well as the jejunum. Right hemicolectomy was performed and histological examination showed nonHodgkin's lymphoma of the large cleaved cell type with a diffuse pattern. A chest radiograph now showed increase in size of the lung lesion in the right lower and left upper zones; cytological examination of the sputum showed lymphoma cells (fig 1). After further staging investigations she was assessed as having stage IIIB disease ${ }^{4}$; combination chemotherapy with ATEP (adriamycin, teniposide, cyclophosphamide, and prednisone) was given with good results. The lung lesions resolved and she remained in complete remission receiving four to six weekly chemotherapy until March 1983, when pulmonary lesions returned together with a right sided pleural effusion. She

Address for reprint requests: Dr A Manoharan, St George Hospital, Kogarah, New South Wales 2217, Australia.

Accepted 10 October 1983 was also noted to have right sided third cranial nerve palsy. Sputum, pleural fluid, and cerebrospinal fluid all showed lymphoma cells on cytological examination. The disease proved to be resistant to further treatment, including radiotherapy, and she died in May 1983. Necropsy was not performed.

CASE 2

A 62 year old woman first presented in May 1981 with abdominal pain and was noted to have a large epigastric mass. At laparotomy a large retroperitoneal mass was found; biopsy and histological examination of this mass showed non-Hodgkin's lymphoma of the large cell type, diffuse pattern. She received radiotherapy of the abdomen to a dose of $4500 \mathrm{cGy}$ (4500 rads) with good results. The epigastric mass, however, reappeared five months later. Staging investigations did not show any evidence of the disease above the diaphragm, and a bone marrow examination

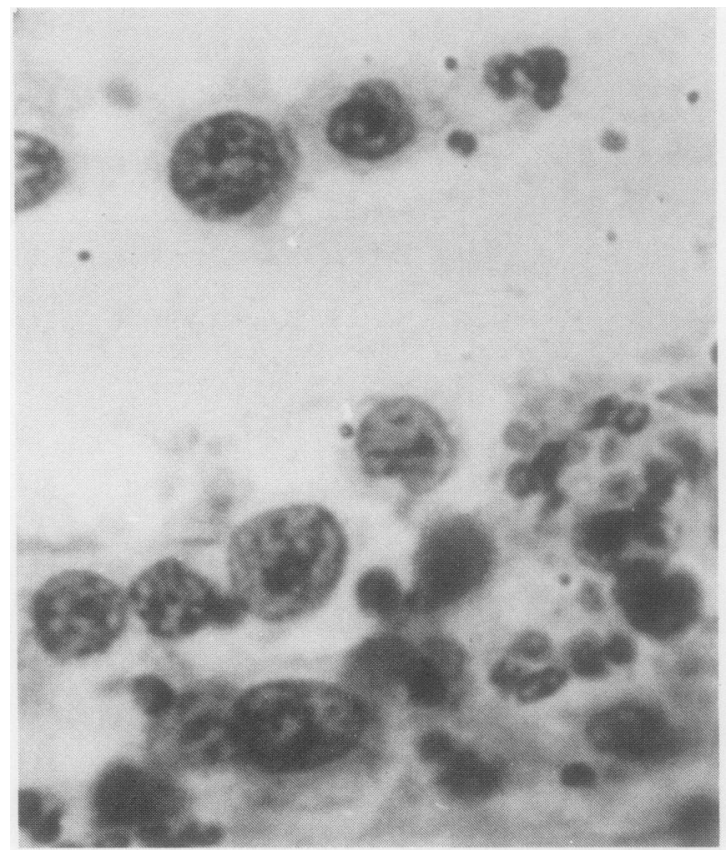

Fig 1 Case 1: Sputum showing single cleaved lymphoma cells. $(\times 485$. $)$ 
showed nothing abnormal. She was treated with combination chemotherapy with ATEP followed by three weekly infusions of another combination chemotherapy, COM (cytosine arabinoside, vincristine, and methotrexate with folinic acid rescue). She received three complete courses of the ATEP-COM regimen with good results Investigations in June 1982 showed complete remission and she remained well until May 1983, when she presented with exertional dyspnoea and dry cough, anorexia, fever, and weight loss. Physical examination showed dullness over the infrascapular and infra-axillary regions on either side, and a chest radiograph showed bilateral hilar lymphadenopathy and also bilateral pleural effusions. After aspiration of the left basal pleural effusion an area of collapse and consolidation became visible in the left lower lobe. Cytological examination of the pleural fluid and sputum showed large lymphoid cells (fig 2), similar to those seen in the original histological sections. She did not appear to have any extrathoracic lymphoma, and she is currently receiving radiotherapy to the thoracic region.

Five consecutive early morning sputum specimens were collected and five direct smears were made from each. The slides were stained with haematoxylin and counterstained by the Papanicolaou method; the Saccomanno technique was not used for this examination as it was thought that this technique, designed to disrupt the mucus, may also disrupt cell patterns and so produce artefactually single cells. ${ }^{5}$

\section{Discussion}

The morphological features of the lymphoid cells seen on

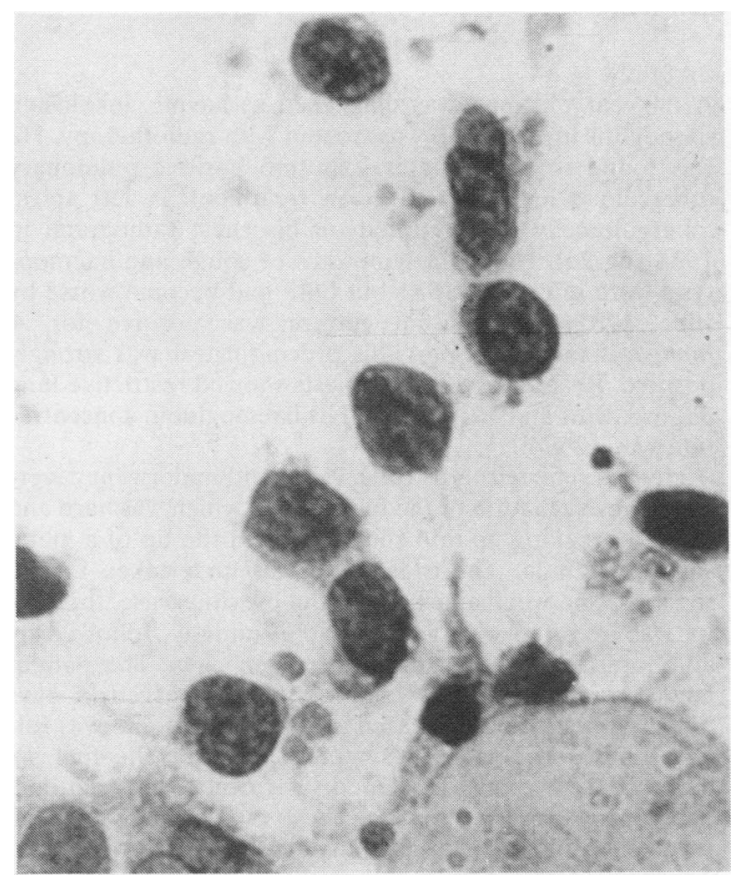

Fig 2 Case 2: Sputum showing single lymphoma cells. (× 485.) cytological examination of the sputum in the two patients were similar to those seen in their original histological sections from the gastrointestinal tract and retroperitoneal nodes respectively. Although the lung lesions in case 1 could have been pseudolymphoma (rather than true malignant lymphoma), which is one form of lymphoid proliferation in patients with Sjögren's syndrome, ${ }^{6}$ the clinical course and the cells seen on cytological examination of the sputum both at presentation and also at relapse suggested true malignancy; furthermore, lymphoma cells, similar to the ones seen in the sputum, were also found in the pleural fluid as well as the cerebrospinal fluid at the time of relapse. The diagnosis of pulmonary lymphoma in case 2 was also further supported by the finding of lymphoid cells in the pleural fluid.

The usefulness of sputum cytology in the diagnosis of pulmonary Hodgkin's disease has been reported previously $^{78}$ but its diagnostic value in pulmonary nonHodgkin's lymphoma has so far had only scant mention in published reports and that only in cytology texts. ${ }^{59}$ Cytological diagnosis of non-Hodgkin's lymphoma and identification of lymphoma cells in the sputum are dependent not only on the histological type of non-Hodgkin's lymphoma but also on the clinical setting and whether the patient is already receiving chemotherapy. Patients receiving chemotherapy may shed cells showing atypia and hyperchromasia, which may be confused with lymphoma cells. Carcinoma of the lung, a rare complication in patients with non-Hodgkin's lymphoma, ${ }^{10}$ must also be considered in the differential diagnosis. Lymphoma cells, however, are shed singly whereas carcinoma usually shows clustering and cell moulding. ${ }^{5}$

We thank Mr WR Clifton for the figures and Mrs M Jenkins for secretarial assistance.

\section{References}

' Manoharan A, Pitney WR, Schonell ME, Bader LV. Intrathoracic manifestation in non-Hodgkin's lymphoma. Thorax 1979;34:29-32.

2 Jenkins PF, Ward MJ, Davies P, Fletcher J. Non-Hodgkin's lymphoma, chronic lymphatic leukaemia and the lung. $\mathrm{Br} J \mathrm{Dis}$ Chest 1981;75:22-30.

${ }^{3}$ Petty TL. The contemporary approach to pulmonary diagnosis. In: Petty TL, ed. Pulmonary diagnostic techniques. Philadelpia: Lea and Febiger, 1975:249-63.

4 Carbone PP, Kaplan HS, Mushoff K, Smithers DW, Tubiana M. Report of the committee on Hodgkin's disease staging classification. Cancer Res 1971;31:1860-1.

${ }^{5}$ Koss LG, ed. Diagnostic cytology and its histopathological basis. Philadelphia: JB Lippincott, 1979:623, 628, 673.

- Anderson LG, Talal N. The spectrum of benign to malignant lymphoproliferation in Sjögren's sydrome. Clin Exp Immunol 1972;10: 199-221.

' Suprun H, Koss LG. The cytological study of sputum and bronchial washing in Hodgkin's disease with pulmonary involvement. Cancer 1964;17:674-80.

${ }^{8}$ Giangreco A, Erringer DS, Dragon LH, Gupta PK, Lenhard RE. Sputum cytologic diagnosis of Hodgkin's disease involving the lung. Arch Intern Med 1980;140:910-3.

${ }^{9}$ Schumann GB, Di Fiore K, Johnston JL. Sputum cytodiagnosis of disseminated histiocytic lymphoma: a case report. Acta Cytol 1983;27:262-6.

${ }^{10}$ Phadke KP, Manoharan A. Adenocarcinoma of the lung in non-Hodgkin's lymphoma. Aust N Z J Med 1979;9:565-7. 